\title{
Role of Surgical Biopsy in Thoracic Swellings
}

\author{
Mir Ishtyak Ahmed ${ }^{1}$ \\ ${ }^{1}$ Dr. Ishtyak Ahmed Mir, MCh, B-Grade, Surgeon Specialist, Community Health Center, Banihal, Jammu and Kashmir, \\ India
}

Address for Correspondence: Dr. Ishtyak Ahmed Mir, R/O, C-1, Old Medical Enclave, Near K.C. Cinema, Jammu, J\&K State, India, E mail: ishtyak_mir@rediffmail.com

\begin{abstract}
Background: Open Surgical biopsy as the first line of investigation is neither practiced by the clinicians nor liked by the patient. Non invasive diagnostic techniques are used for initial evaluation of a swelling, but these facilities are not available every where. The study was conducted to know the results of open surgical biopsy in patients with cervico thoracic and other body swellings. Material and Methods: The study included 49 patients, mostly females, majority in $2^{\text {nd }}$ to $3^{\text {rd }}$ decade of life, youngest a 7 year old girl and the eldest a 68 year old male. $75 \%$ of the patients presented with swelling, $100 \%$ had clinically palpable swelling and cervico thoracic region was involved in more than $90 \%$ of the patients. Under local anesthesia open surgical biopsy was done in all. Results: Histopathology revealed tuberculosis in $63.26 \%$ and malignancy in $20.40 \%$ of the patients. All patients with anterior chest wall swellings had malignancy. $79.59 \%$ of the patients were definitely helped by accurate diagnosis and specific treatment. There was no morbidity related to the surgical procedure. Conclusion: It is recommended that open surgical biopsy should always be performed in any patient with a suspicious swelling, and where facilities for non invasive investigation and sophisticated investigation are not available. It not only helps in making and excluding a diagnosis, but also helps in providing specific treatment to the patient.
\end{abstract}

Key words: Excision, Swelling, Tuberculosis.

\section{Introduction}

Except for very little pathology, diagnosis of any swelling cannot be easily made with certainty even if the constitutional symptoms are present and a detailed history is available. Patients with enlarged lymph nodes, subcutaneous swelling can present with varied or no symptoms. A provisional clinical diagnosis may be made, but that even if correct may not be of any help, especially in patients who may require prolonged specific antimicrobial treatment, surgical intervention, radio chemotherapy or a multimodality treatment. A detailed history, thorough general / systemic examination and non invasive diagnostic methods are currently the procedures of choice for initial evaluation, but then they are not the gold standard in all swellings [1] that makes tissue biopsy mandatory for the clinician to arrive at a specific diagnosis and for the patient to receive the best possible specific treatment. There is no

Manuscript received: $1^{\text {st }}$ Sept 2015

Reviewed: $4^{\text {th }}$ Sept 2015

Author Corrected: $10^{\text {th }}$ Sept 2015

Accepted for Publication: 23 ${ }^{\text {rd }}$ Sept 2015 denying the fact that while subjecting every swelling to biopsy unnecessary biopsies may be done in some patients who have benign pathology [2], but than in an area where facilities for non invasive diagnostic procedures are not available, where some diseases are very common, or clinical suspicion is that of having a biopsy, in such a situation (except in patients who have squamous carcinoma metastatsis from head or neck primary, where excision biopsy may lead to higher local treatment failure) one should always go for open surgical biopsy. The study was conducted to find alternative to non invasive diagnostic techniques and to find the results of open surgical biopsy. It is a fact that general surgeons perform highest number of biopsies in all such swellings [3], if that be so every general surgeon in a community health centre should perform such procedures as and when required.

\section{Material and Methods}


The study was conducted in a community health center (CHC), over a period of 3 years. All patients with clinical history of swelling / mass on any part of body associated with, cough, fever, weakness, palpitations, pain, dyspnea, and physical examination suggestive of anemia and or variegated consistency palpable mass in any part of the body, were included in the study. A detailed history with regard to duration of symptoms, initial site / size, shape, increase or decrease in swelling / mass, pain, fever, and treatment history was also recorded. A thorough general physical and systemic examination was performed in all the patients. Complete blood count (ESR, CBC-PBF), Liver, kidney functions, blood sugar, ECG, X-Ray chest, sputum in suspects, and routine urine examination was done. Every attempt was made to convenience the patient to go for fine needle aspiration (FNAC), other non invasive evaluation of the swelling at higher centre's, however, those who refused or those who could not afford were explained the merits and demerits of biopsy, and further subsequent treatment which is needed at referral or a tertiary care institutes. All the biopsies are to be done under local anesthesia was explained to the patients and their attendants.

All the swellings which had symptomatic, clinical, operative and macroscopic features of lipoma, sebaceous cyst, collection, hematoma, abscess, midline dermoids, neurofibroma, besides thyroid and breast swellings were not included in the study. After negative xylocaine sensitivity test and anesthesia to the local area surgical biopsy also called open biopsy, was done as, (i) Incisional biopsy, which removed only part of the swelling / suspicious area, enough to make a diagnosis, or (ii) Excisional biopsy which removed the entire swelling, tumor or abnormal area, for both a diagnostic and therapeutic intent.. The specimen so obtained was sent for histopathological examination to the pathologist. Further management plan was decided as per the histopathology report. Patients with histopathological evidence of tuberculosis, were registered at the nearest health centre in consultations with the specialist and given anti tubercular treatment (ATT) as per regime, all patients with reports suggesting malignancy were referred to higher centers for specialized treatment. Patients were followed in outdoor department, further evaluation or alterations in treatment was done, morbidity and mortality in patients coming for follow up was recorded.

\section{Results}

The study included 31 female and 18 male patients, majority were in $2^{\text {nd }}$ through $3^{\text {rd }}$ decade of life, the youngest was a 7 years old girl and the eldest a 68 years old male. Swelling on any part of body was the commonest symptom ( Table 1), and palpable swelling / lymphadenopathy, anemia were the common clinical signs, cervical nodes were enlarged in majority (Table 2, Figure 1). The symptomatology varied from 3-10 months, and the size of the swelling ranged from 2 to 15 $\mathrm{cm}$. $08.16 \%$ of patients had purulent discharge from neck. Anemia and raised ESR was observed in more than $50 \%$ of patients. Local anesthesia was used in all, excision of whole swelling / node was done in $75.51 \%$ of patients (Figure 2), histopathology confirmed tuberculosis in $63.26 \%$ of patients, malignancy in $20.40 \%$ which was more in male patients (Table 3). Of the $10.20 \%$ patients with anterior chest wall (thoracic) swelling (Figure 3, 4 and 5), all had malignancy ( in two of these $4.08 \%$ the diagnosis was made after definitive surgery at a tertiary care centre), of the $6.12 \%$ patients with inguinal swelling, $66.66 \%$ had tuberculosis and one $(33.33 \%)$ had metastatic deposits of seminoma testis, all $6.12 \%$ patients with abdominal wall swellings, had terminal malignancy, of the $4.08 \%$ patients with gluteal swellings one had malignancy. In spite of the best possible efforts, clinical, operative and macroscopic diagnosis made by the operating surgeon was proved wrong by histopathology in $16.32 \%$ of patients. $14.28 \%$ of patients had associated pulmonary tuberculosis and $6.12 \%$ had initially taken erratic ATT, $6.12 \%$ had sputum positive for acid fast bacilli. All patients with tuberculosis were put on ATT, in consultation with the specialist and higher centers in the field. In tubercular group $16.12 \%$ of the patients persisted with symptoms and developed other complications of tuberculosis, which were managed systematically, and by alternative regime. $12.90 \%$ of the patients with tuberculosis did not respond to treatment and died, $83.87 \%$ of the patients were cured and were disease and swelling free at a follow up of 5 years. $4.08 \%$ of the patients with benign pathology from our study turned out to have malignant disease after the whole tumor was excised and subjected to histopathological examination at a tertiary care centre. The wrong diagnosis could have been either we had not excised adequate tissue or we had not taken tissue from specific site. Patients with malignancy were referred to higher centers, and were followed in outdoor. Of the $20.20 \%$ patients with malignancy $40 \%$ died with in 1 year, $10 \%$ had either died or lost to follow up, but $50 \%$ were alive at follow up of 5 years. 


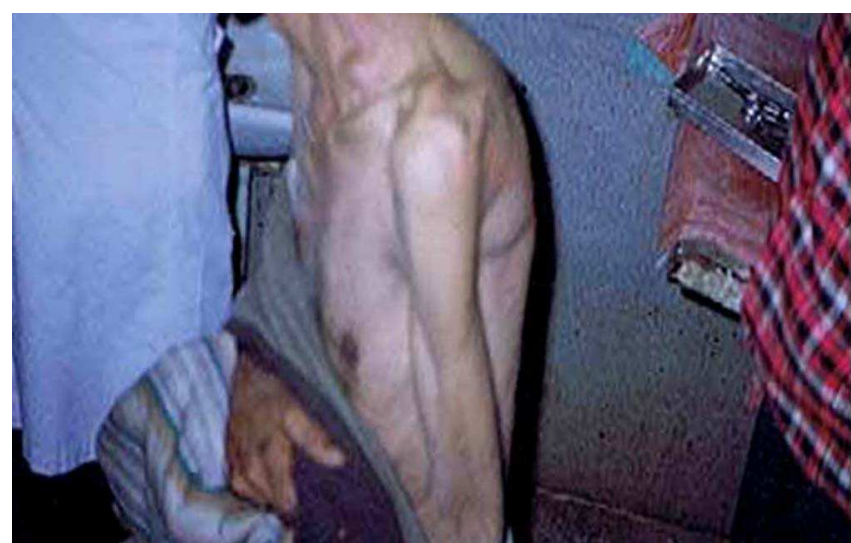

Fig 1: Swelling in left supraclavicular region (tubercular) (hemangiopericytoma)

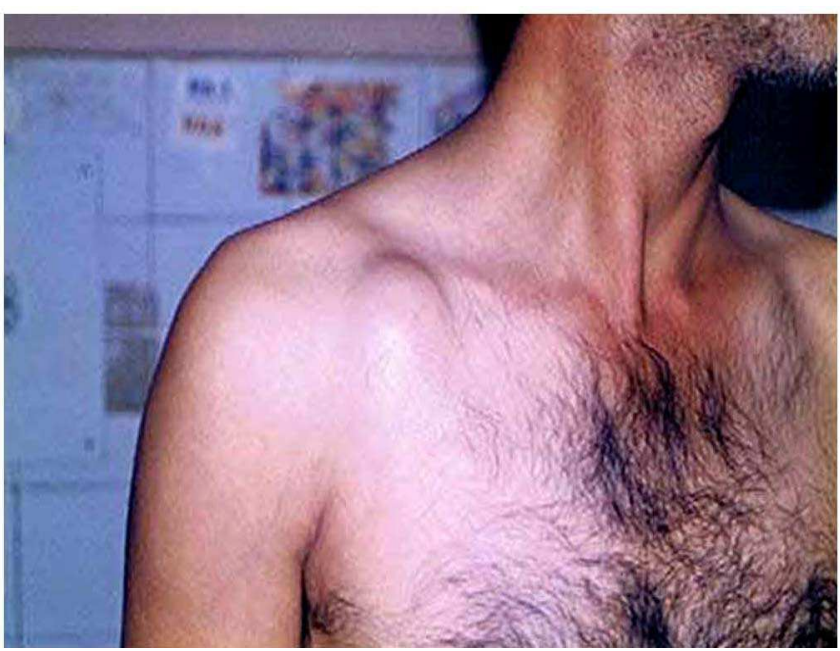

Fig 3: Swelling in right infraclavicular region

(Immediate grade fibrosarcoma)

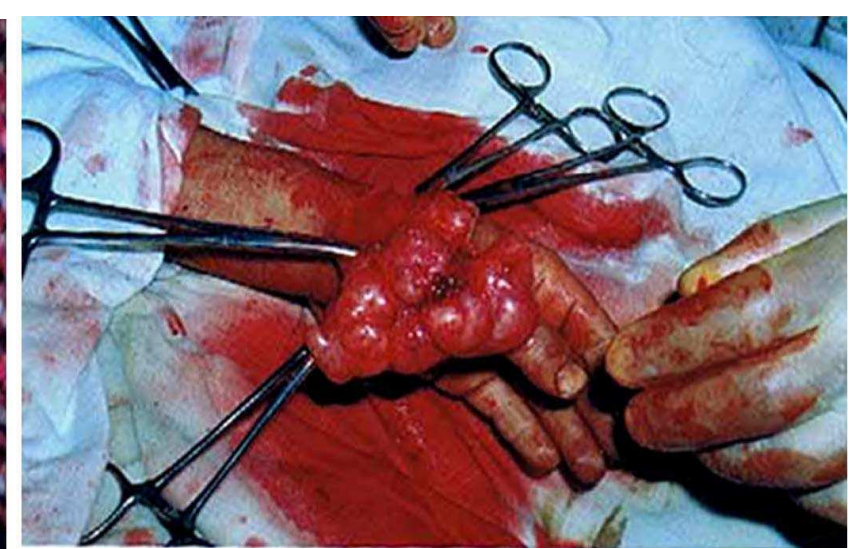

Fig 2: Swelling over wrist being excised

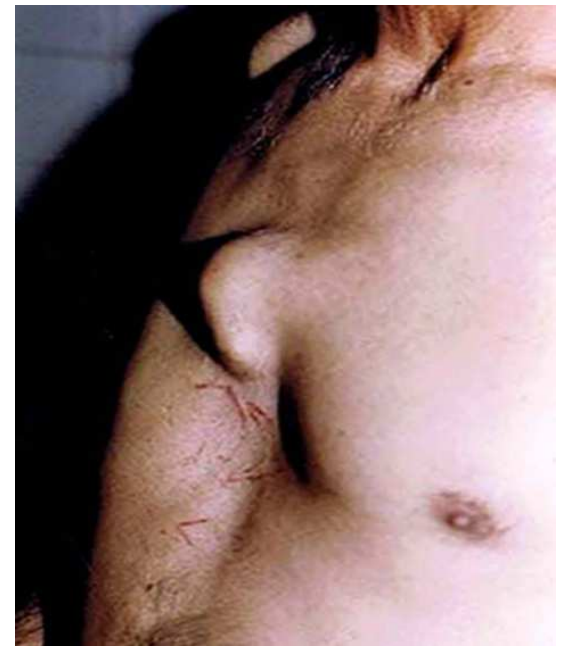

Fig 4: Swelling over lower part of sternum

(Chondrosarcoma)

Excision biopsy helped in making the diagnosis, and 39 patients $(79.59 \%)$ were definitely helped by accurate diagnosis, and specific treatment, besides diagnosis also helped in convincing these patients to go for treatment at higher centers.

Table 1: Symptomatology in 49 patients with swellings*

\begin{tabular}{|l|l|l|l|l|}
\hline Symptoms & Number of patients & Percentage & Male & Female \\
\hline Swelling & 37 & 75.51 & 11 & 26 \\
\hline Cough & 20 & 40.81 & 03 & 17 \\
\hline Fever & 18 & 36.73 & 03 & 15 \\
\hline Palpitations & 15 & 30.61 & 05 & 10 \\
\hline Weakness & 14 & 28.57 & 03 & 11 \\
\hline Dyspnea & 11 & 22.44 & 06 & 05 \\
\hline Pain & 09 & 18.36 & 03 & 06 \\
\hline
\end{tabular}

*More than one symptom was present in a patient 
Table 2: Showing region wise swellings with clinical signs*

\begin{tabular}{|l|l|l|l|l|}
\hline Region of swelling & Number of patients & Percentage & Male & Female \\
\hline Cervical & 36 & 73.46 & 10 & 26 \\
\hline Tenderness & 10 & 20.40 & 06 & 04 \\
\hline Axillary & 07 & 14.28 & 02 & 05 \\
\hline Thoracic & 05 & 10.20 & 04 & 01 \\
\hline Draining sinus Neck & 04 & 08.16 & 02 & 02 \\
\hline Inguinal & 03 & 06.12 & 01 & 02 \\
\hline Abdominal wall & 03 & 06.12 & 02 & 01 \\
\hline Limbs & 03 & 06.12 & 01 & 02 \\
\hline Gluteal & 02 & 04.08 & 00 & 02 \\
\hline
\end{tabular}

*More then one region was involved, and more than one swelling was present in some patients.

Table 3: Diagnosis of patients after histopathological examination*

\begin{tabular}{|l|l|l|l|l|}
\hline Histopathological Finding & Number of Patients & Percentage & Male & Female \\
\hline Tuberculosis & 31 & 63.26 & 05 & 26 \\
\hline Non Specific / Lipoma / Fibro lipoma & 06 & 12.24 & 04 & 02 \\
\hline Non Hodgkin's lymphoma & 02 & 04.08 & 01 & 01 \\
\hline
\end{tabular}

*Two patients with benign pathology turned out to have malignancy after definitive surgery at a higher centre. In addition the diagnosis of Embryonal rhabdo myosarcoma, Ewing's Sarcoma, Metastatic deposits of carcinoma, Intermediate grade fibro sarcoma, Poorly differentiated Sarcoma, Metastatic deposits of Seminoma, Squamous cell Carcinoma, Hemangiopericytoma, Schwanoma, and Pleo morphic adenoma was made in ten patients.

\section{Discussion}

Any unexplained swelling on body with or without constitutional symptoms, not only warrants a detailed history and clinical examination, but also that a tissue diagnosis is the only specific method of managing such swellings in a more scientific way. There are various types of biopsy procedures, each type of biopsy has pros and cons. The choice of which type to use depends on things like site, size, numbers, how suspicious the tumor looks, other medical problems the patient may have, and surgeons personal preferences. A surgeon should talk to his patient about the pros and cons of different types of biopsy procedures, but in rural hospitals and in a set up like ours where there is neither any provision of FNAC, nor of core needle biopsy, neither of ultrasound / CT / MRI guided, nor of stereotactic core needle biopsy, nor of vacuum assisted core biopsy the only option left is that of open surgical biopsy. Besides the results of these biopsy procedures are not as good as that of open surgical biopsy, the only advantage being that all these procedures are noninvasive, and can be performed without any suture. Surgical biopsy can be done in the hospital's outpatient department, or in the operation room under local anesthesia, sedation may be needed in uncooperative patients and children's. Stitches are needed, and it will leave a scar, but then it is the most ideal way of making a diagnosis in a rural hospital where there is no other facility available and the patients are not willing to go to higher centers for one or the other reason. The only requirement is that of a qualified surgeon who should know when to cut, why to cut, how to cut, how much to cut, why not to cut, how to handle an abnormal cut, how to handle the specimen so cut and how to manage the patient with a multidisciplinary approach after any adverse histopathology repost is received. This study has small number of patients but is significant in view of the fact that accurate diagnosis was established in $83.68 \%$ of patients and all were put on specific treatment, also the numbers may not be significant given the fact that we had tried to biopsy only the highly suspicious swelling, but then that may be another interesting point because the diagnosis of common swellings such as sebaceous and others not included in this study is always made clinically, and such swellings should not be included in differential diagnosis of swelling in patients with tuberculosis, lymphoma, or other malignancies.

Tubercular lymphadenitis being more in females is well known [4], very high percentage of patients with 
tuberculosis in the present study may be because of the fact that there is ignorance, illiteracy, non availability of specialized diagnostic procedures in remote areas, peoples leaving as joint families, in congested houses, and still believe in treatments from quacks. Majority of the patients having tubercular lymphadenitis is almost similar to the observation made in patients from Southeast Asia and India who have special predilection for tubercular lymphadenitis [5,6]. Slowly increasing swelling with varied duration is in accordance to studies where it has been observed that tubercular lymphadenitis usually presents as a slowly increasing painless swelling of a single group of lymph nodes, duration of symptoms may vary from 3 to 8 months, and duration of symptoms is more in men $[7,8]$. The lymph node size may vary from 3 to $10 \mathrm{~cm}$ and only 10 $35 \%$ of the nodes may be tender during examination, and about 4- $11 \%$ can have draining sinus [9], similar observations have been made in the present study. Unilateral involvement of 1-3 nodes has been noted in $85 \%$ of the cases [5], cervical node involvement is most common and is reported in $45 \%-70 \%$ of cases, with majority in supraclavicular region and almost $20 \%$ bilateral $[9,10]$. Constitutional symptoms in present study are in accordance to those of other studies [8,9]. Excisional biopsy though an invasive approach has the highest sensitivity and may produce a more rapid and favorable symptomatic response [7].

The findings of multisite lymphadenopathy in present series is in consistence with reported findings of other studies, but is at variance with regard to the diagnosis of non-Hodgkin's lymphoma of $21 \%$, compared to only $2.04 \%$ in present study [11]. The difference could be our study was from rural area where tuberculosis is very common, and also where all patients do not report to our hospital, more over the diagnosis of non Hodgkin's lymphoma in $21 \%$ is from a series of 297 patients, even though ours is very small series, we differ with the reported observation that lymphoma is a common cause of surgical lymphadenopathy [3]. More then $50 \%$ of the patients in the present study having tuberculosis is in contrast to the reported incidence of only $8.5 \%$ in United States [12].

If not comparable in figures, but a similar study of diagnostic biopsy of lymph nodes of the neck, axilla and groin had shown over all 34\% malignant disease including $19 \%$ lymphoreticular, $15 \%$ metastatic, $15 \%$ tubercular lymphadenitis, and 5\% benign, non-specific, self limiting disease [5], though the numbers are variable yet are specific to the extent that malignancy was detected in $24.48 \%$ of patients in present study also,(which included $4.44 \%$ after definitive surgery at higher centre) The difference could be because we had included whole body swellings, and the number was quiet less compared to other series, more over the present study was conducted only in swellings where patient had variegated consistency swelling and high suspicion of underlying tubercular or malignant pathology. Availability of specific diagnosis helps manage these patients in a scientific way. Most of the patients in present study got specific treatment, and $81.63 \%$ of patients were alive, without recurrence and in good health at a follow up of 5 years.

The study has confirmed the facts that the patient in rural areas and in areas where medical facilities are lacking present very late, most of their time is wasted by quacks, they may not get proper professional advice in time, medical facility may be lacking and majority can't effort to go to higher centers for diagnosis and treatment. Also the number can't be taken as specific because very few patients seek medical advice at one health centre.

\section{Conclusion}

In conclusion open surgical biopsy is easy to perform, can be performed in any health centre, requirement of a qualified surgeon is must, should not be delayed and a specific diagnosis is certain. We recommend if non invasive approaches have failed or are not available, or the diagnosis is in doubt one should always go for open surgical biopsy.

Funding: Nil

Conflict of interest: None.

Permission of IRB: Yes

\section{References}

1. Lefebvre JL, Coche-Dequeant B, Van JT, Buisset

E, Adenis A. Cervical lymph nodes from an unknown primary tumor in 190 patients. Am J Surg. 1990 Oct;160(4):443-6.

2. Lee YT, Terry R, Lukes RJ. Biopsy of peripheral lymph nodes. Am Surg. 1982 Oct;48(10):536-9.

3. Morris-Stiff G, Cheang P, Key S, Verghese A, Havard TJ. Does the surgeon still have a role to play in the diagnosis and management of lymphomas? World J Surg Oncol. 2008 Feb 4;6:13. doi: 10.1186/1477-7819-6-13. 
4. Chen YM, Lee PY, Su WJ, Perng RP. Lymph node tuberculosis: 7-year experience in Veterans General Hospital, Taipei, Taiwan.

Tuber Lung Dis. 1992 Dec;73(6):368-71.

5. Wark P, Goldberg H, Ferson M, McKenzie D, Lau E, Rivas K. Mycobacterial lymphadenitis in eastern Sydney. Aust N Z J Med. 1998 Aug;28(4):453-8.

6. Menon K, Bem C, Gouldesbrough D, Strachan DR. A clinical review of 128 cases of head and neck tuberculosis presenting over a 10 year period in Bradford, UK. J Jaryngol Otol. 2007 Apr;121(4):362-8. Epub 2006 Aug 21.

7. Artenstein AW, Kim JH, Williams WJ, Chung RC. Isolated peripheral tuberculous lymphadenitis in adults: current clinical and diagnostic issues. Clin Infect Dis. 1995 Apr;20(4):876-82.

8. Purohit MR, Mustafa T, Mørkve O, Sviland L. Gender differences in the clinical diagnosis of tuberculous lymphadenitis--a hospital-based study from Central India. Int J Infect Dis. 2009 Sep;13(5):600-5. doi: 10.1016/j.ijid.2008.06.046. Epub 2008 Dec 25.

9. Khan FY. Clinical pattern of tuberculous adenitis in Qatar: experience with 35 patients. Scand J Infect Dis. 2009;41(2):128-34. doi: $10.1080 / 00365540802578991$.

10. Shriner KA1, Mathisen GE, Goetz MB. Comparison of mycobacterial lymphadenitis among persons infected with human immunodeficiency virus and seronegative controls. Clin Infect Dis. 1992 Oct;15(4):601-5.

11. Moor JW, Murray P, Inwood J, Gouldesbrough D, Bem C. Diagnostic biopsy of lymph nodes of the neck, axilla and groin: rhyme, reason or chance? Ann R Coll Surg Engl. 2008 Apr;90(3):221-5. doi: $10.1308 / 003588408 X 242105$

12. CDC. Reported tuberculosis in the United states, 2008, Atlanta, GA; U.S. Department of Health and Human Services, CDC; 2009. Sep 2009.

\section{How to cite this article?}

Mir Ishtyak Ahmed. Role of Surgical Biopsy in Thoracic Swellings. Int J Med Res Rev 2015;3(9):953-958. doi: 10.17511/ijmrr.2015.i9.177. 